\title{
SIMPLIFIED TRUSS MODEL FOR PRESTRESSED CONCRETE SLENDER BEAMS
}

\author{
Manakan LERTSAMATTIYAKUL ${ }^{1}$, Junichiro NIWA ${ }^{2}$, \\ Satoshi TAMURA ${ }^{3}$ and Yuzuru HAMADA ${ }^{4}$ \\ ${ }^{1}$ Member of JSCE, Ms. Eng., Graduate Student, Dept. of Civil Eng., Tokyo Institute of Technology \\ (2-12-1 O-okayama, Meguro-ku, Tokyo 152-8552, Japan) \\ E-mail: 96b31110@cv.titech.ac.jp \\ 2 Fellow of JSCE, Dr. Eng., Professor, Dept. of Civil Eng., Tokyo Institute of Technology \\ ${ }^{3}$ Member of JSCE, Research Engineer, Research and Development Center, DPS Bridge Works Co., Ltd. \\ ${ }^{4}$ Member of JSCE, Dr. Eng., Research and Development Center, DPS Bridge Works Co., Ltd.
}

\begin{abstract}
The parametric study using FEM has been performed to investigate the factors thought to influence on the shear mechanism of PC slender beams. With the main investigation on the effects of prestressing force with its type of stress distribution, the failure mechanism can be clarified. The simplified truss model has been developed with a small number of degrees of freedom for assessing the shear carrying capacity of PC slender beams based on the equivalent linear analysis. By utilizing the extrapolated inclination of critical stress flow and the thickness of diagonal compression members estimated from the FEM results, the well-predicted results on the shear behavior of PC slender beams without transverse reinforcement can be obtained.
\end{abstract}

Key Words : simplified truss model, PC slender beam without transverse reinforcement, shear carrying capacity, parametric study using finite element analysis

\section{INTRODUCTION}

Currently, there are several modern constructions in which the high resistance and the prevention of crack occurring in serviceability stage are extremely required. Undoubtedly, by taking the advantage of prestressing force as the axial force, prestressed concrete (PC) members can be applied to respond these requirements perfectly. Hence, the clarification of failure mechanism and the development of analytical approach or model for evaluating the shear carrying capacity of PC structural members are necessary. Even the fundamental structures such as PC slender beams, the reasonable explanation for the actual failure behavior has not been achieved. Unlike the reinforced concrete (RC) beams, due to the prestressing force as axial force, PC beams are usually found to fail in shear compressive mode of failure, even in cases of PC slender beams, where the shear span to effective depth ratio, $a / d$, is greater than or equal to $2.5^{1)}$.

In the recent methods for assessing the shear carrying capacity of PC slender beams, most of them are proposed based on the empirical equation without the clarification of effect of significant factors. For example in ACI $\operatorname{code}^{2)}$, the equation is being proposed without the clear expression of effect of prestressing force and the comparatively conservative results are usually obtained. For the decompression moment method which is the method recommended by $\mathrm{JSCE}^{3)}$, the scatter of predicted results is usually observed due to the neglecting of distribution of the prestressing force. Moreover, there is another method considering the resistance at the flexural crack occurring as the additional value to the shear resistance due to the contribution of compression, called $\mathrm{M}_{\mathrm{cr}}$ method ${ }^{4}$. However, it was found that this method cannot be used to give the comprehensive explanation about the shear compression failure of PC slender beams and how the resistance of the flexural crack occurring remains until the ultimate stage. To solve the mentioned shortcomings of current methods in evaluating the shear carrying capacity of PC slender beams, newly proposed analytical method is expected to include the following 3 improvements. 1) The ability in clarifying the mechanism of shear compression failure of PC beams. 2) The clear consideration of effect of significant factors on the shear behavior, especially the prestressing force and its type of stress distribution. 3) The simplicity in modeling with the objective outcome and high accuracy in prediction. 
In this research, the parametric study using the finite element method (FEM) has been carried out in order to investigate the failure mechanism of PC slender beams influenced by the variation of many significant parameters. The tendency of stress flows obtained from analytical results is summarized and applied to propose the analytical model including the foregoing mentioned 3 improvements, named the simplified truss model. The proposed simplified truss model has been utilized to evaluate the shear carrying capacity of PC slender beams without transverse reinforcement. The comparisons of shear carrying capacity and failure patterns between the predicted and the experimental results are performed to confirm the applicability of the proposed model.

\section{PARAMETRIC STUDY USING FINITE ELEMENT ANALYSIS}

\section{(1) Finite element analysis}

The nonlinear finite element analysis using DIANA system has been conducted to examine the failure mechanism of PC slender beams without transverse reinforcement. Owing to the symmetric property of a beam, PC slender beams are modeled into a half of specimen with an 8 node quadrilateral isoparametric plane stress element in a two dimensional configuration as shown in Fig. 1. Details of geometric properties of the analytical model are demonstrated in the figure, where $h$ is height of the model, $r_{l}$ and $r_{s}$ represent the width of loading plate and support, respectively.

In the analysis, the smeared crack model is applied as the crack model to concrete elements. As the constitutive model under compressive stress states (Fig. 2(a)), concrete is assumed to behave elastically up to $1 / 3$ of the compressive strength, $f_{c}$. The proper power function is adopted to express the behavior until the peak value. The equation proposed by Popovics ${ }^{5)}$ is used as post-peak path. After cracking, the tension softening model named one-fourth model is applied as the concrete constitutive model under tension as illustrated in Fig. 2(b). The yield conditions of Drucker-Prager and Rankine are utilized as the failure criteria for compression and for tension, respectively. The reinforcement elements are modeled to have the perfect bond with concrete. The bilinear elasto-plastic model of steel is adopted for the longitudinal reinforcement. The prestressing force is applied at the first step of the analysis by using the incorporated prestressing command in DIANA system. For the displacement control, the displacement of $0.5 \mathrm{~mm}$ is applied for each step.

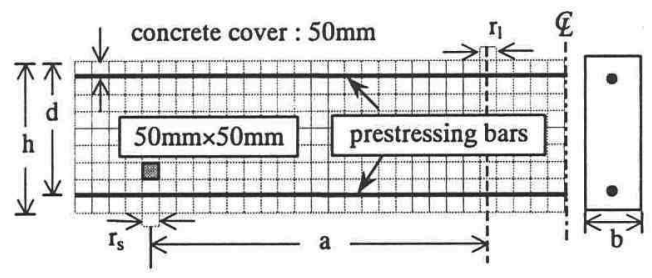

Fig. 1 Finite element analytical model and its cross section applied in the parametric study

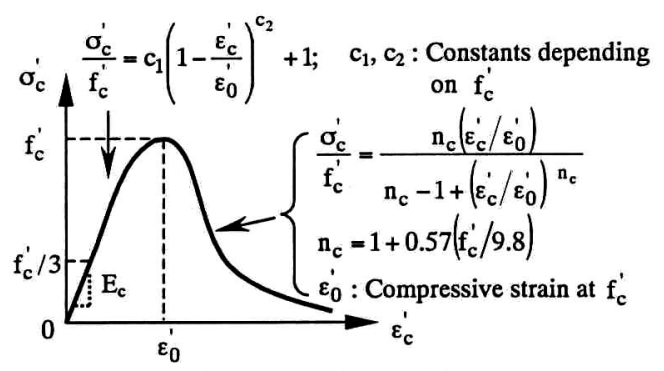

(a) Compression model

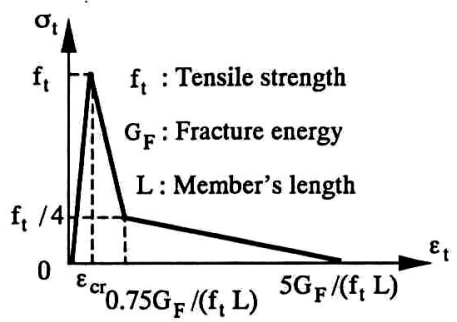

(b) Tension model

Fig. 2 Constitutive models for concrete

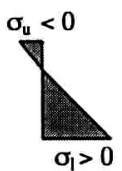

Triangle with minus upper fiber stress : $\operatorname{tri}(-)$

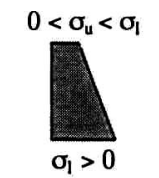

Trapezoid : tra

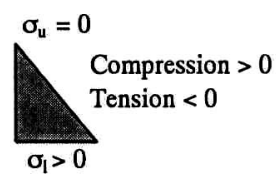

Triangle with zero upper fiber stress : $\operatorname{tri}(0)$

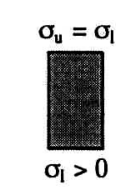

Rectangle : rec
Fig. 3 Types of stress distribution due to prestressing force

\section{(2) Parametric study}

In the parametric study, as the major investigation, the values of prestressing force, $P$, in upper and lower prestressing bars are proportionally adjusted considering the types of stress distribution as shown in Fig. 3. The values of $P$ are changed in the range of $100-400 \mathrm{kN}$. From the values of $P$ and the location of applied axial force, the upper and lower fiber stresses ( $\sigma_{k}$ and $\sigma_{l}$, respectively) are calculated and varied in 
the range of $-3 \sim 6$ and $1 \sim 15 \mathrm{MPa}$, respectively. The value of $\sigma_{u}$ is set not to create the cracks at the upper portion of the beams. The values of $\sigma_{l}$ is assumed based on the permissible stress $(=15 \mathrm{MPa})$ in Specification of Highway Bridges ${ }^{6}$. In Fig. 3, from the values of $\sigma_{u}$ and $\sigma_{l}$, the types of stress distribution can be categorized into 4 types, such as triangle with minus (tension) upper fiber stress, triangle with zero upper fiber stress, trapezoid, and rectangle. Here, the prestressing level under compression and tension are expressed in terms of plus and minus values, respectively. The values of the shear span to effective depth ratio, $a / d$, the effective depth, $d$, and the compressive strength of concrete, $f_{c}^{\prime}$, are also considered as the parameters playing an important role on shear behavior. The values of $a / d$ were changed from 2.5 to 4.5 with the variation of $d$ from 400 to $800 \mathrm{~mm}$ while the beam width, $b$, is set to be $200 \mathrm{~mm}$. The compressive strength of 40 and 80 $\mathrm{MPa}$ are correspondingly used as the representatives of normal and high strength concrete. The longitudinal reinforcement ratio is set to be $1.3 \%$ (yield strength: $f_{p y}=930 \mathrm{MPa}$ ) for all cases.

\section{(3) Tendency of analytical results}

From the analytical results, due to the externally applied load, after the flexural cracks occurred, the

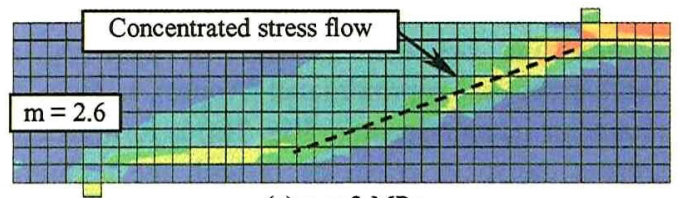

(a) $\sigma_{1}=3 \mathrm{MPa}$

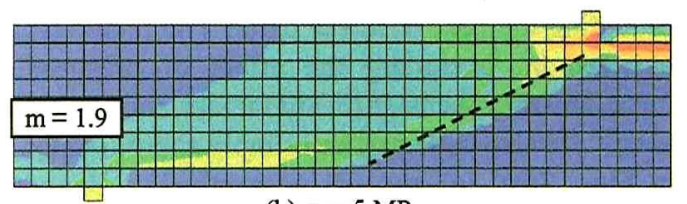

(b) $\sigma_{1}=5 \mathrm{MPa}$

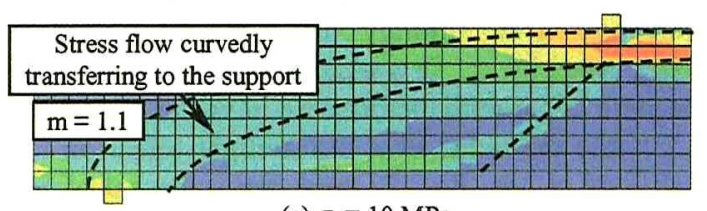

(c) $\sigma_{l}=10 \mathrm{MPa}$

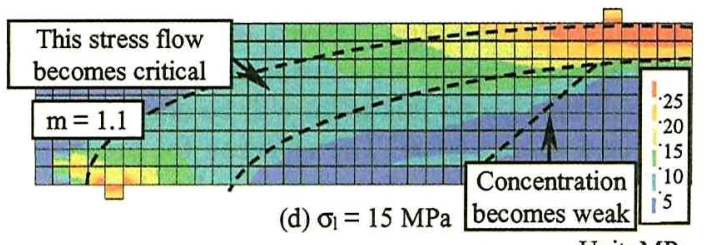

Fig. 4 Analytical results of parametric study with variation on $\sigma_{l}$ where $\sigma_{\mathrm{u}}=0 \mathrm{MPa}$ $\left(\mathrm{a} / \mathrm{d}=3.5, \mathrm{~d}=400 \mathrm{~mm}\right.$ and $\left.\mathrm{f}_{\mathrm{c}}{ }^{\prime}=40 \mathrm{MPa}\right)$ diagonal crack generated similar to the case of RC slender beams. Even though the diagonal crack took place, the beams were still able to resist the applied load. A crushing of concrete occurred in the upper portion near the loading point and then the beams reached the ultimate stage. All cases are predicted to fail in shear compressive mode of failure.

In Fig. 4, the contour figures of stress flow at $90 \%$ analytical resistance at the ultimate stage $\left(90 \% \mathrm{~V}_{\max }\right)$ of PC slender beams under triangle with zero upper fiber stress distribution $\left(\sigma_{u}=0 \mathrm{MPa}\right)$ are expressed. The example values of $\sigma_{l}$ are varied from 3 to $15 \mathrm{MPa}$ (compression $>0$ ). For expressing how flat of the slope of concentrated stress flow, parameter $m$ is introduced. The definition and evaluation of $m$ will be explained later. From the figure, with the increase in $\sigma_{l}$, the slope of the concentrated stress flow (dashed line) becomes steeper. When the value of $\sigma_{l}$ becomes larger, the concentration of this steep stress flow becomes weak, while the stress flow curvedly transferring from the loading point to the support becomes remarkable. It is noteworthy that, due to the prestressing force, not only the resistance along the diagonal crack, but the resistance due to the stress flow curvedly transferring to the support also exists.

Figure 5 illustrates the comparison between the difference in types of stress distribution is

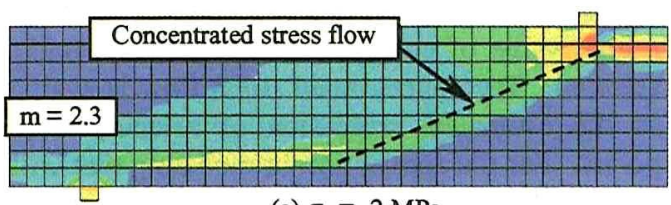

(a) $\sigma_{\mathrm{u}}=-2 \mathrm{MPa}$

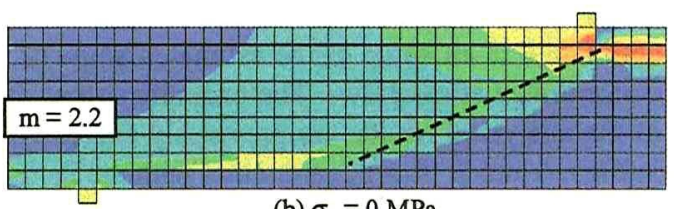

(b) $\sigma_{\mathrm{u}}=0 \mathrm{MPa}$

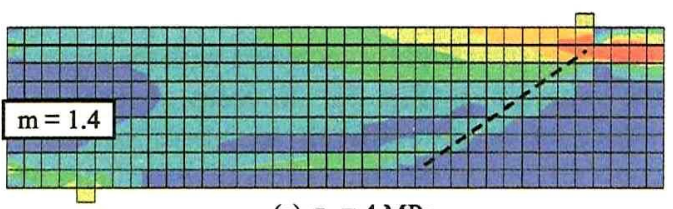

(c) $\sigma_{\mathrm{u}}=4 \mathrm{MPa}$

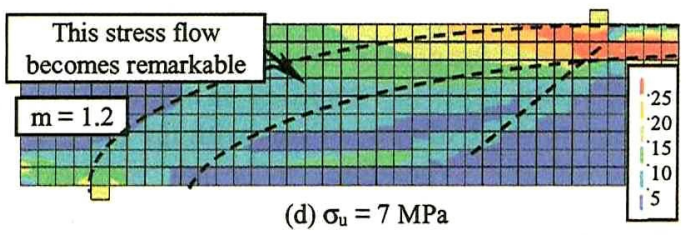

Fig. 5 Analytical results of parametric study Unit: $\mathrm{MPa}$ with variation on $\sigma_{\mathrm{u}}$ where $\sigma_{\mathrm{l}}=7 \mathrm{MPa}$ $\left(\mathrm{a} / \mathrm{d}=3.5, \mathrm{~d}=400 \mathrm{~mm}\right.$ and $\left.\mathrm{f}_{\mathrm{c}}{ }^{\prime}=40 \mathrm{MPa}\right)$ 
performed. It is found that, with the increase in value of $\sigma_{u}$, the inclination of concentrated stress flow becomes slightly steeper. While, the stress flow curvedly transferring to the support becomes stronger with the greater value of $\sigma_{u}$. It can be said that not only the value of $\sigma_{l}$, but the value of $\sigma_{u}$ also influences on the inclination of concentrated stress flow. The shear carrying capacity becomes evidently different when the inclination of the concentrated stress flow changes. It means that the effect due to the upper fiber stress cannot be neglected. Hence, if the tendency of inclination of the concentrated stress flow can be estimated, the critical flow of stresses in the actual beam can be predicted in any conditions of geometric properties and axial forces.

For estimating the inclination of the concentrated stress flow, the values of principal compressive stress, $\sigma_{2}$, at each Gauss's point are taken into the consideration. As illustrated in Figs. 6(a) and (b), between the upper and lower longitudinal bars the location of the maximum absolute values of $\sigma_{2}$ of each horizontal level, $\sigma_{2 i-\max }$, are plotted with the solid circles. By considering the location of $\sigma_{2 i-\max }$ as the co-ordination in X-Y axes, $\left(x_{i}, y_{i}\right)$, the correlation coefficient can be calculated from the expression as shown in Fig. 6(a). This value is used to express the agreement between the estimated equation and the selected data. A part of Gauss's points, which gives a high value of correlation coefficient $(z 0.95)$, is selected. The concentrated stress flow is evaluated as the estimated expression of selected Gauss's points. For the application in modeling that will be explained in the following section, the concentrated stress flow is summarized in terms of $m$, where $m=$ $\cot \theta$ and $\theta$ is an angle of the estimated slope of the concentrated stress flow. The example values of $m$ of the analytical results are previously expressed as in Figs. 4 and 5. It is apparent that with the increase in the value of $\sigma_{l}$, the value of $m$ decreases (the concentrated stress flow becomes steeper in Fig. 4). The value of $m$ slightly decreases with the increase in the value of $\sigma_{u}$ (Fig. 5). In cases of large $\sigma_{l}$, the values of $m$ are difficult to assess because the concentration of the steep stress flow becomes weak, while the critical stress flow turns into one which curvedly transfers to the support. The evaluated inclination of the critical stress flow in this case will be different from the tendency in the other cases where the value of $m$ decreases with the increase in value of $\sigma$. Therefore, it is not practical in summarizing the values of $m$. To summarize the values of $m$ in the same trend (value of $m$ decreases with the increase in value of $\sigma_{l}$ ), even the concentration of the steep stress flow becomes weak

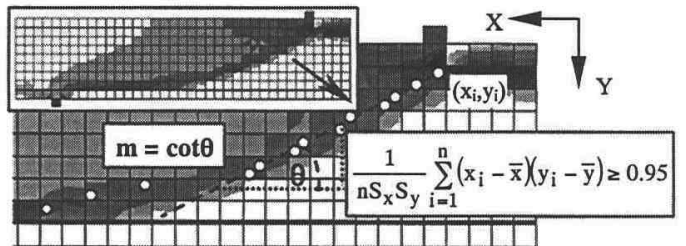

$\mathrm{S}_{\mathrm{x}}, \mathrm{S}_{\mathrm{y}}$ : Standard deviation of $\mathrm{x}$ and $\mathrm{y} \overline{\mathrm{x}}, \overline{\mathrm{y}}$ : Mean of $\mathrm{x}$ and $\mathrm{y}$ $\mathrm{n}$ : Number of considered

(a) General cases

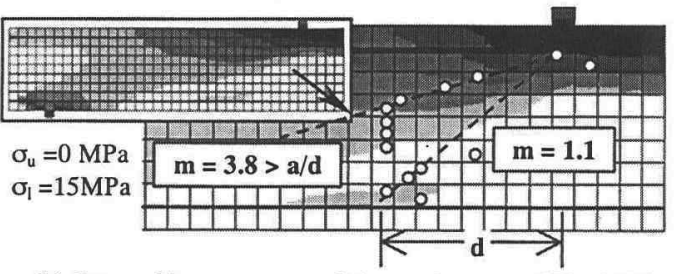

(b) Cases of large $\sigma_{l}$ or $\sigma_{u}>0$ (example: case of Fig.4 (d))

Fig. 6 Evaluation of inclination of concentrated stress flow in terms of $m(m=\cot \theta)$

in cases of large $\sigma_{l}$, the slope of this steep stress flow is applied to assess the values of $m$ for this case. Then, the evaluation of $m$ for the case like this as the example in Fig. 4(d) is demonstrated in Fig.6(b). For this kind of evaluation of $m$, the horizontal range of $d$ from the loading point is taken into the consideration. In Fig. 7(a), from the finite element analytical results (FEM) in the parametric study, the relationships between $m$ and $\sigma_{l}$ with $\sigma_{u}$ are summarized and approximated (Approx.). Here, the parameter $\sigma_{m}$ mentioned in Fig. 7(a) is formulated to express the main effect of $\sigma_{l}$ with the additional effect of $\sigma_{u}$ and the constants are set as ones providing the best fit to the data. The relationships between $m$, excluding the effect of prestressing force, and the other significant factors, such as $a / d, d$, and $f_{c}$ ' are also collected and simply approximated as in Figs. 7(b), (c) and (d), respectively. From the approximated equations, it is confirmed that, the values of $m$ are strongly influenced by $\sigma_{l}$ with an extra effect by $\sigma_{u}$. It is noticed that the values of $m$ become larger with the increase in values of $a / d$ and $f_{c}$ ', while the value of $d$ has a slight effect on the value of $m$. In Fig. 7, there are some calculated results which show the different tendency to the estimated relationships. Based on the simplicity, these approximations are considered to be adequate. More discussion on this point will be done with the predicted results later. The equation for predicting the value of $m$ can be expressed as in Eq. 1 .

$$
\mathrm{m}=2.55\left(\left(1+0.2 \frac{\sigma_{u}}{\sigma_{u}+\sigma_{l}}\right) \sigma_{l}\right)^{-\frac{3}{5}}\left(\frac{a}{d}\right)\left(\frac{f_{c}^{\prime}}{100}\right)^{\frac{3}{5}}
$$




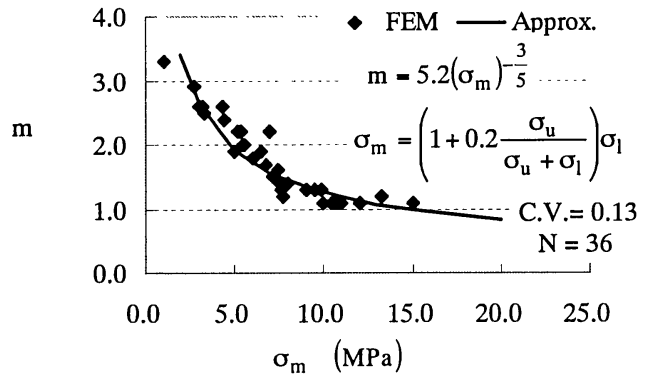

(a) Effects of $\sigma_{l}$ and $\sigma_{u}\left(a / d=3.5, d=400 \mathrm{~mm}, \mathrm{f}_{\mathrm{c}}{ }^{\prime}=40 \mathrm{MPa}\right)$

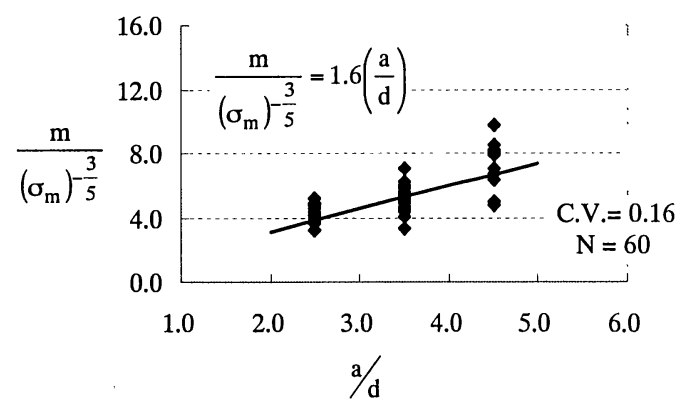

(b) Effects of a/d (d=400 mm, $\left.\mathrm{f}_{\mathrm{c}}{ }^{\prime}=40 \mathrm{MPa}\right)$

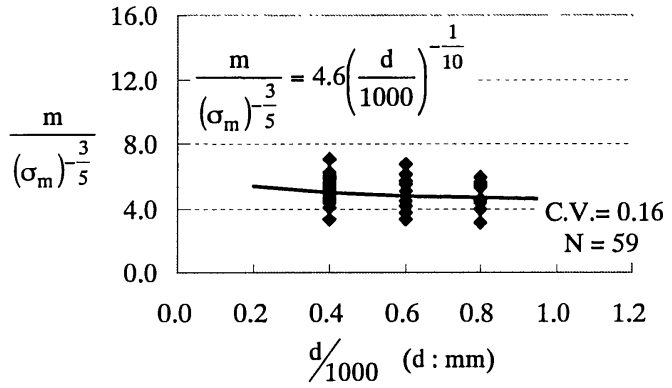

(c) Effects of $d\left(a / d=3.5, f_{c}{ }^{\prime}=40 \mathrm{MPa}\right)$

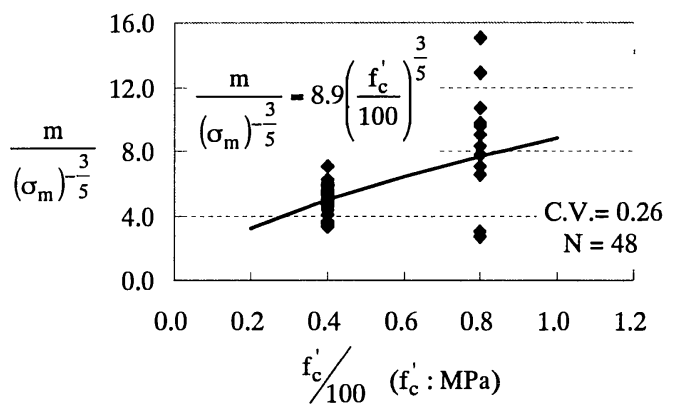

(d) Effects of $f_{c}{ }^{\prime}(a / d=3.5, d=400 \mathrm{~mm})$

Fig. 7 Relationships between $m$ and the significant parameters thought to effect to shear failure mechanism

\section{SIMPLIFIED TRUSS MODEL}

\section{(1) Fundamental principles}

Figure 8 shows the simplified truss model developed in this study to calculate the shear carrying capacity of PC slender beams without transverse reinforcement. As one of the main concept of this study that the simple and objective method is preferable, the simplified truss model with a small number of degrees of freedom (7 nodes and 11 members) is assumed. The proposed model is fixed in X-direction at both nodes along the center line and in Y-direction at the support. The model is subjected by the shear force, $V$, and prestressing forces, $\mathrm{P}_{1}$ and $\mathrm{P}_{2}$, as depicted in the figure. The proposed model is divided into 3 regions, which are $\mathrm{D}$-region due to the applied load, D-region due to the support, and B-region. Here, D-region is the zone where the flow of stresses is comparatively complicated, whereas B-region is the zone where the flow of stresses is quite uniform compared with D-region ${ }^{7}$. The modeling of concrete consists of flexural compression members, transverse tension members and diagonal compression members. The reinforcement is modeled into flexural tension members. For simplicity in modeling, the 2 diagonal compression members representing the stress flows from the loading point, members [3] and [4], are

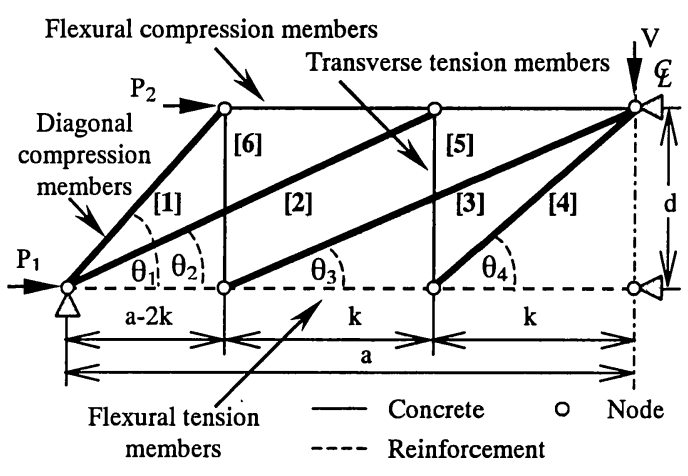

Fig. 8 Schematic diagram of PC slender beam in the simplified truss model (without transverse reinforcement)

assumed to have the same horizontal interval in the level of flexural tension members $(=k$ in Fig. 8, where $k$ is a constant). The total cross sectional area of longitudinal bars, $A_{p s}$, is employed as the cross sectional area of the flexural tension member. The cross sectional area of flexural compression member is set to be $2 c b$, where, $c$ is the concrete cover of upper portion. The thicknesses of transverse tension members [5] and [6] are assumed to be the distance from the loading point to the middle point between 2 transverse tension members $(=1.5 k$ in Fig. 8$)$ and the left distance to the middle point of the support (= $a-1.5 k$ in Fig. 8), respectively. It is recognized that, 
in shear compression failure, the thickness of diagonal compression members is important for evaluating the resistance of a concrete structure. Thus, the estimation of the reasonable thickness of the diagonal compression members based on the finite element analytical results has been done and the results are discussed in the following section.

\section{(2) Evaluation of thickness of the diagonal compression members, $w$}

With the purpose of assessing the thickness of diagonal compression members, $w$, the compressive stresses in the vertical direction at each Gauss's points, $\sigma_{y i}$, at about $90 \%$ of $V_{\max }$ are considered. As the example in Fig. 9(a), the range of $0.2 d$ below the upper prestressing bar is investigated. In order to avoid the effect of cracking in the middle height portion of the beam (the effect on the value of $\sigma_{y i}$ ), the range $0.2 d$ is enough for an investigation. In this considered range, three horizontal levels of Gauss's points are demonstrated as the example in Fig. 9(a). Here, the integration scheme of $2 \times 2$ Gauss's points are employed. Figure 9(b) shows the distribution of the ratio of $\sigma_{y i}$ and the maximum values in that horizontal level, $\sigma_{y i-\max },\left(\Delta_{i}=\sigma_{y i} / \sigma_{y i-\max }\right)$ along the beam axis. It is noticed that the value of $\Delta_{i}$ is comparatively large in the range right below the loading plate. For each horizontal level of Gauss's point in the range of $0.2 d$, the horizontal width of the distribution, $t_{i}$, where the value of $\Delta_{i}$ is equal to 0.3 is measured. The horizontal width of distribution at this ratio is considered to be quite moderate and this ratio $\left(\Delta_{i}=0.3\right)$ is not too low to be affected by the disturbance as shown in the figure. The average value of $t_{i}$ is considered as the horizontal thickness of the concentrated stress flow, $t$. For a clear example, the distribution of the values of $\Delta_{i}$ in each horizontal level of Gauss's points are presented separately in Fig. 9(b). The range in the vicinity area of the support above the lower prestressing bar is also treated with the same process to evaluate the horizontal width of the distribution. Figure $\mathbf{1 0}$ shows the samples of obtained horizontal thickness in the vicinity area of a loading point, $t_{l}$, and support, $t_{s}$, from FEM analytical results with the variations of prestressing level, types of stress distribution, effective depth and width of bearing plates. In Fig.10, white and black squares represent the horizontal thickness measured in the vicinity area to the loading point and support, respectively.

Based upon the previous study ${ }^{1}$, the width of the bearing plate, $r$, is an important factor to the failure behavior of PC slender beams failed in shear compression mode of failure. The horizontal

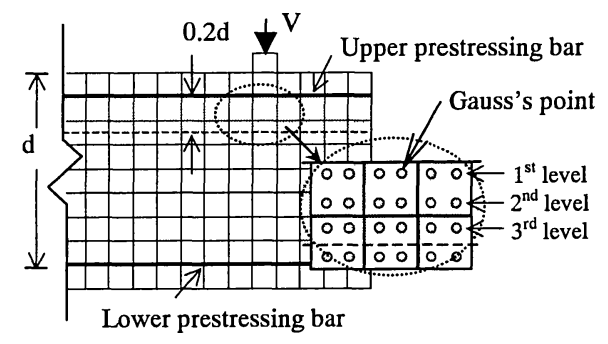

(a) Example of Gauss's point in the considered range

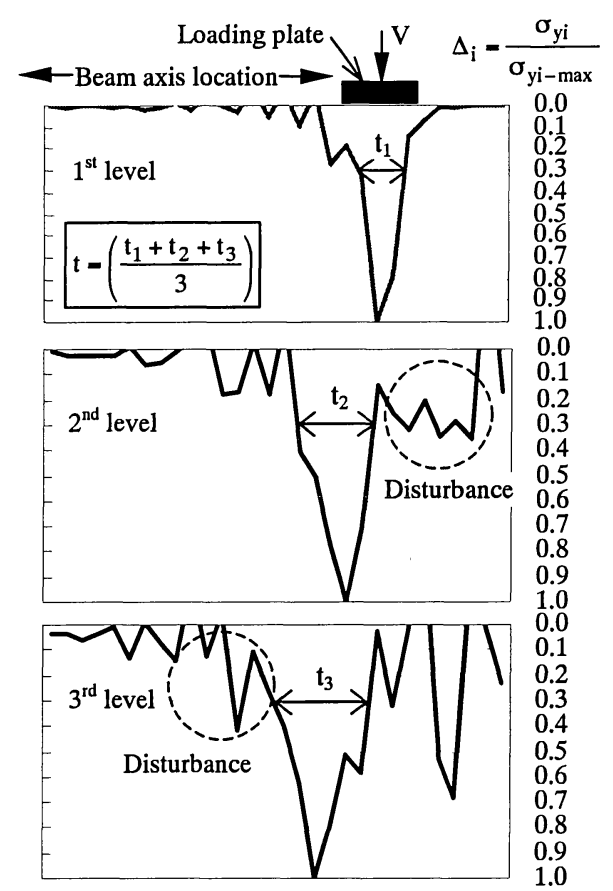

(b) Ratio of the distributed stress

Fig. 9 Evaluation of horizontal thickness of diagonal compression member from FEM analytical results

thickness of diagonal compression members is estimated in terms of width of the loading plate, $r_{l}$, or support, $r_{s}$, with the effective depth, $d$. As depicted in Fig. 10, in many variations of prestressing level and geometric properties, it is found that the values of $t_{l}$ and $t_{s}$ can be simply approximated as $r_{l}+0.1 d$ and $2\left(r_{s}+0.1 d\right)$, respectively. The solid and dashed lines stand for the approximated values of $t_{l}$ and $t_{s}$, respectively, where the values of $r$ and $d$ are adopted from each case. Due to the geometric conditions of PC slender beams where $a / d \geq 2.5$, the thinner strut compared with RC deep beams is expected to be created. Hence, it is reasonable that the value of $t_{l}$ is smaller than the horizontal thickness of a strut in case of RC deep beams ${ }^{8)}, r+0.3 d$.

In the proposed model (as the example in Fig. 8), the members [1]-[2], and members [3]-[4] are considered to be effected by the support and the 


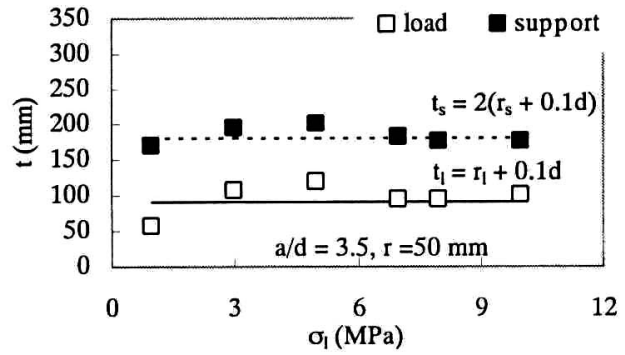

(a) Variations of $\sigma_{1}\left(\sigma_{u}=0 \mathrm{MPa}\right)(\mathrm{d}=400 \mathrm{~mm})$

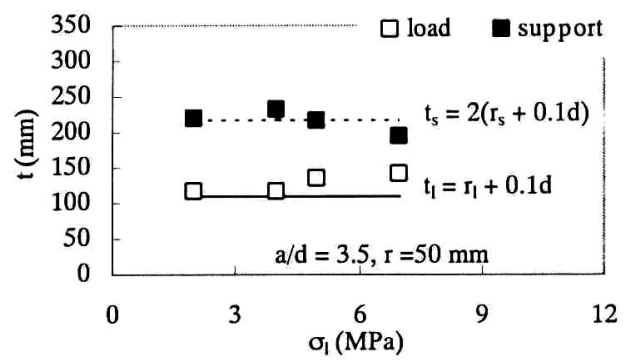

(b) Variations of $\sigma_{l}\left(\sigma_{u}=0 \mathrm{MPa}\right)(\mathrm{d}=600 \mathrm{~mm})$

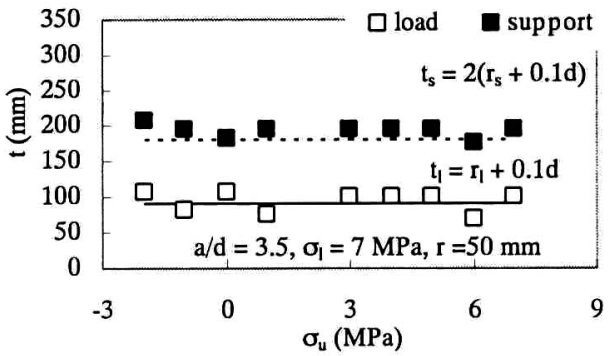

(c) Variation of types of stress distribution ( $d=400 \mathrm{~mm}$ )

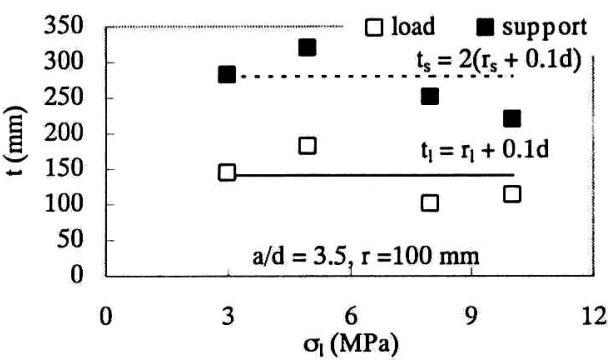

(d) Variations of $\sigma_{1}\left(\sigma_{u}=0 \mathrm{MPa}\right)$ with $r(d=400 \mathrm{~mm})$

Fig. 10 Samples of measured and approximated horizontal thickness

loading plate, respectively. Thus, the thicknesses of the diagonal compression members affected by the loading plate, $w_{l}$, and the support, $w_{s}$, are proposed to be $\left(r_{l}+0.1 d\right) \sin \theta_{i}(i=3,4)$ and $2\left(r_{s}+0.1 d\right) \sin \theta_{i}(i=1$, $2)$, respectively, where each $\theta_{i}$ is mentioned in Fig. 8.

However, the influence of the loading plate in terms of $w_{l}$, is considered not to come out in wide region. It is recognized that there is a limit in the applicable range of the thickness affected by the loading plate to the member [3]. As the reference cases, the analysis of $\mathrm{RC}$ slender beams with varied values of a/d and $d$ are carried out. From the analytical results of $\mathrm{RC}$ slender beams, the values of $m$ assessed from the inclination of the diagonal crack are estimated about 2.0 as summarized in Fig. 11. Hence, the applicable range of the thickness affected by the loading plate to the member [3] should be less than $2.0 d$ from the loading point. The details of the proposed model will be explained as follows.

\section{(3) Division of modeling}

In this study, the proposed simplified truss model has been designed by taking an account of the value of $m$ relating with the possible location of the critical diagonal compression member. Based on the results of parametric study (as in Figs. 4 and 5), the failure mechanism of PC slender beams can be divided into 2 types. One takes place along the concentrated stress flow (Model 1), and the other one occurs along the stress flow curvedly transferring to the support (Model 2). Thus, the proposed approach is simply

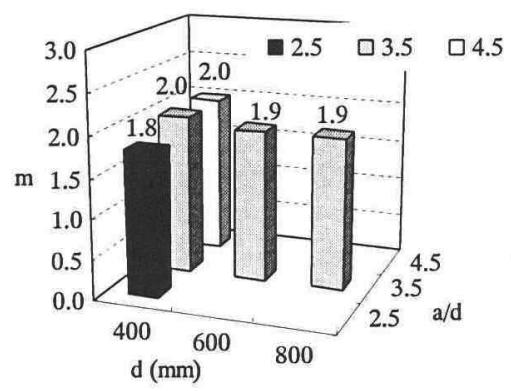

Fig. 11 Values of $m$ evaluated from the inclination of the diagonal crack in $\mathrm{RC}$ slender beams

divided into 2 models and demonstrated comparing with the contour figure of FEM results as in Fig. 12.

For Model 1 where $m>1.0$ : The distance $m d$ is adopted as the horizontal distance from the loading point to the ended node of member [3] as shown in Fig. 12(a). Based on the foregoing investigation on RC slender beams, when $m \geq 2.0$, the effect of the loading plate is considered to become weak. Hence, the thickness of member [3] is set to be $(a-m d) \sin \theta_{3}$, where $a-m d \leq d$. When the inclinations of diagonal compression members are comparatively flat in case of $m \geq 2.0,50 \mathrm{~mm}$ is set to be a lower bound value of $w_{i}$ in order to avoid the underestimation. By considering the effect of the region close to the support, the applied upper bound value of $m$ is set to be $0.9(a / d)$ in modeling. The specimen with prestressing stress up to the medium level is considered to match with this model.

For Model 2 where $m \leq 1.0$ : As illustrated in Fig. 
12(b), the distance $m d$ is utilized as the horizontal distance from the loading point to the ended node of member [4]. The effect of bearing plates on the size of members [2] and [3], which are expressing the stress flow curvedly transferring to the support, is considered to be small. Then, the thicknesses are set to be $m d \sin \theta_{2}$ and $(a-2 m d) \sin \theta_{3}$, where $a-2 m d \leq d$. As previously shown in Fig. 4, the larger value of $\sigma_{l}$ is, the value of $m$ becomes smaller. When $m$ is estimated to be comparatively small, the critical stress flow cannot generate in a quite closed area to the loading point. As a result, the curved stress flow to the support becomes a critical portion like the example in Fig. 12(b). Thus, for the specimen with high prestressing stress level, the possible failure zones should be the area close to the loading point or the area along the curved flow to the support (as emphasized in the contour figure).

\section{(4) Compression softening parameter, $\eta$}

Since the failure behavior is principally governed by the diagonal compression members, the influence of existing cracks on the decrease in the stiffness of concrete should be incorporated. To obtain the reliable value of shear carrying capacity, the value of compression softening parameter, $\eta$, employed in the calculation is important. Generally, the equation based on the consideration of the change of perpendicular tensile strain proposed by Vecchio and Collins $^{9}$ is applied. For the simplified truss model, more complicated processes are required in order to be able to adopt this equation. But it would be a way against the concept of this study. Thus, the practical and reasonable equation of $\eta$ is simply established and it is linearly varying on $f_{c}$ ' with a slight variation from 0.6 to 0.4 in the range of $f_{c}$ ' of 30 to $100 \mathrm{MPa}$ as in Eq. 2.

$$
\eta=-0.3\left(\frac{f_{c}^{\prime}}{100}\right)+0.7
$$

The compression softening parameter is employed in the calculation of the resistance capacity of concrete members in the next section.

\section{(5) Process of calculation}

The process in calculating of the shear carrying capacity of PC slender beams by using the simplified truss model is recapitulated in Fig. 13. After calculating the value of $m$ from Eq. 1, the simplified truss model can be modeled based on the division in the previous section (Fig. 12). By applying the external shear force, $V$, each member force, $F_{i}$, can be assessed. Due to the proposed simplified truss model is indeterminate, the member forces cannot

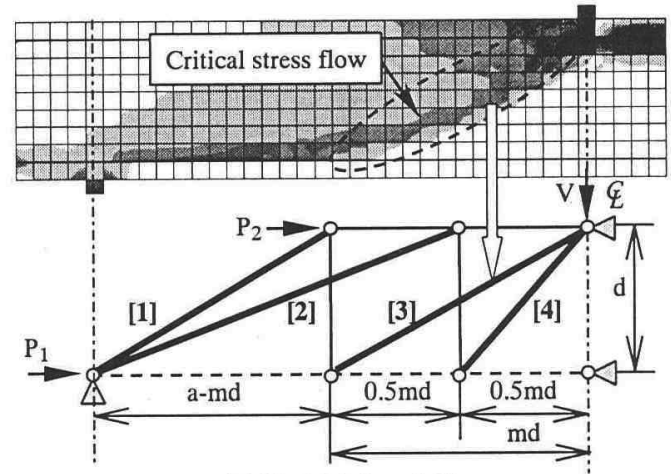

(a) Model $1(\mathrm{~m}>1.0)$

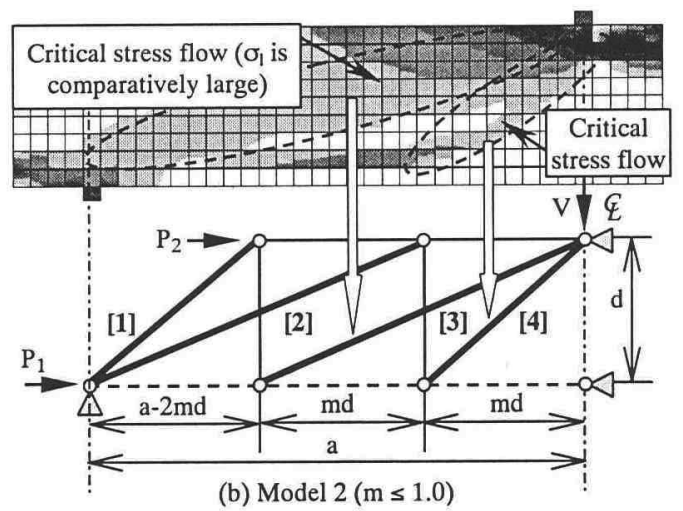

Fig. 12 Division of the simplified truss model

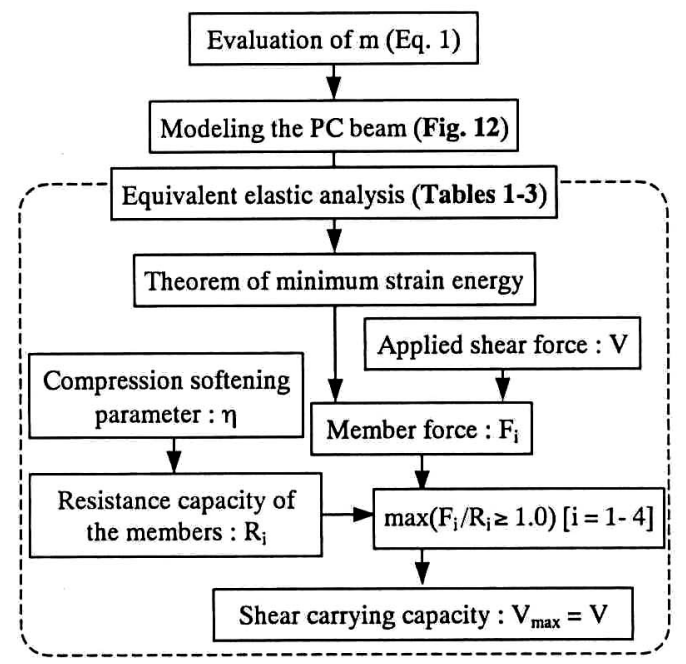

Fig. 13 Process in calculating the shear carrying capacity

easily be calculated by using the balance of forces at each node. Hence, from Castigliano's second theorem, i.e. the theorem of minimum strain energy is applied for solving the values of member forces.

As the main purpose is to evaluate the shear carrying capacity, the calculation of deformation is neglected in this study. For simplicity in calculating the shear carrying capacity of a PC beam, the 
equivalent elastic analysis of the simplified truss model has been carried out. That is, in order to express the behavior of concrete at failed stage, the stiffness of concrete at the ultimate stage as the secant modulus, and the concrete softening, $\eta$, are incorporated to the diagonal compression members. The resistance capacity of each diagonal compression member, $R_{i}$, can be obtained from the compressive strength considering the compression softening parameter, $\eta$, the cross sectional area, $A_{i}$, and the inclination of each member. By comparing the value of $R_{i}$ with $F_{i}$, the shear carrying capacity of the beam can be determined when one of the diagonal compression members becomes critical $\left(F_{i} / R_{i} \geq 1.0\right)$. The resistance capacity of each diagonal compression members, $R_{i}$, and member force, $F_{i}$, are tabulated in Table 1 . Since the failure of PC slender beams is considered to be shear compression mode of failure, the equations of only 4 diagonal compression members, which are considered to govern this kind of failure, are summarized in the table. The cross sectional area of each member $\left(A_{i}\right)$ are summarized in Table 2. For evaluating each member force, $F_{i}$, the expressions, $C_{j k}(j=1-8, k=1-4)$, calculated from the theorem of minimum strain energy are simply tabulated in Table

Table 1 Member force $\left(F_{i}\right)$ and resistance capacity $\left(R_{i}\right)$ of diagonal compression members*

\begin{tabular}{|c|c|c|c|c|}
\hline & Member [1] & Member [2] & Member [3] & Member [4] \\
\hline $\mathrm{F}_{\mathrm{i}}$ & $\frac{\sin \theta_{3}}{\sin \theta_{1}} \mathrm{~F}_{3}$ & $-\frac{\sin \theta_{3}}{\sin \theta_{2}} \mathrm{~F}_{3}-\frac{\mathrm{V}}{\sin \theta_{2}}$ & $\mathrm{~F}_{3}$ & $-\frac{\sin \theta_{3}}{\sin \theta_{4}} \mathrm{~F}_{3}-\frac{\mathrm{V}}{\sin \theta_{4}}$ \\
\hline $\mathbf{R}_{\mathrm{i}}$ & $-\eta \mathrm{f}_{\mathrm{c}}^{\prime} \mathrm{A}_{1} \sin \theta_{1}$ & $-\eta \mathrm{f}_{\mathrm{c}}^{\prime} \mathrm{A}_{2} \sin \theta_{2}$ & $-\eta \mathrm{f}_{\mathrm{c}}^{\prime} \mathrm{A}_{3} \sin \theta_{3}$ & $-\eta \mathrm{f}_{\mathrm{c}}^{\prime} \mathrm{A}_{4} \sin \theta_{4}$ \\
\hline
\end{tabular}

*: The shear force $V$ is applied in terms of plus value.

Table 2 Cross sectional area of each member $\left(A_{i} ; i=1-6\right)$

\begin{tabular}{|c|c|c|c|c|c|c|}
\hline & & $\mathrm{A}_{1} \& \mathrm{~A}_{4}$ & $\mathrm{~A}_{2}$ & $\mathrm{~A}_{3}$ & $\mathrm{~A}_{5}$ & $\mathrm{~A}_{6}$ \\
\hline \multirow{2}{*}{$\begin{array}{l}\text { Model } 1 \\
(\mathrm{~m}>1.0)\end{array}$} & $\mathrm{m}>1.0$ & \multirow{3}{*}{$\begin{array}{c}A_{1}=2\left(r_{s}+0.1 d\right) b \sin \theta_{1} \\
A_{4}=\left(r_{1}+0.1 d\right) b \sin \theta_{4}\end{array}$} & \multirow{2}{*}{$2\left(r_{s}+0.1 d\right) b \sin \theta_{2}$} & $\left(r_{1}+0.1 d\right) b \sin \theta_{3}$ & \multirow{2}{*}{$0.75 \mathrm{mdb}$} & \multirow{2}{*}{$(a-0.75 m d) b$} \\
\hline & $\mathrm{m} \geq 2.0^{*}$ & & & $(\mathrm{a}-\mathrm{md}) \mathrm{b} \sin \theta_{3}{ }^{* *}$ & & \\
\hline \multicolumn{2}{|c|}{$\begin{array}{l}\text { Model } 2 \\
(\mathrm{~m} \leq 1.0)\end{array}$} & & $m d b \sin \theta_{2}$ & $(a-2 m d) b \sin \theta_{3}^{* * *}$ & $1.5 \mathrm{mdb}$ & $(a-1.5 m d) b$ \\
\hline
\end{tabular}

$*: w_{i}(i=1-4) \geq 50 \mathrm{~mm} ; w_{i}:$ thickness of member $[i] \quad * *:(a-m d) \leq d \quad * * *:(a-2 m d) \leq d$

Table 3 Expressions of components $\left(C_{j k}\right)$ calculated from the theorem of minimum strain energy for evaluating member force*

\begin{tabular}{|c|c|c|c|c|}
\hline $\mathrm{j}$ & $\mathrm{C}_{\mathrm{j} 1}$ & $\mathrm{C}_{\mathrm{j} 2}$ & $\mathrm{C}_{\mathrm{j} 3}$ & $\mathrm{C}_{\mathrm{j} 4}$ \\
\hline 1 & $\frac{1}{\mathrm{n}_{\mathrm{u}} \mathrm{A}_{\mathrm{ps}}}$ & $\left(\cos \theta_{3}\right)^{2}\left(a-m_{1} d\right)$ & $-2\left(a-m_{1} d\right) \frac{\cos \theta_{3} \sin \theta_{3}}{\tan \theta_{4}}$ & $\left(a-m_{2} d\right)\left(\frac{\sin \theta_{3}}{\tan \theta_{4}}\right)^{2}$ \\
\hline 2 & $\frac{1}{n A_{c}} d\left(\sin \theta_{3}\right)^{2}$ & $\frac{\mathrm{m}_{1}}{\left(\tan \theta_{1}\right)^{2}}$ & $-\frac{2 m_{2}}{\tan \theta_{1} \tan \theta_{2}}$ & $\frac{\mathrm{m}_{2}}{\left(\tan \theta_{2}\right)^{2}}$ \\
\hline 3 & $\mathrm{~d}\left(\sin \theta_{3}\right)^{2}$ & $\frac{1}{\left(\sin \theta_{1}\right)^{3} A_{1}}+\frac{1}{\left(\sin \theta_{2}\right)^{3} A_{2}}$ & $\frac{1}{\left(\sin \theta_{3}\right)^{3} A_{3}}+\frac{1}{\left(\sin \theta_{4}\right)^{3} A_{4}}$ & $\frac{1}{A_{5}}+\frac{1}{A_{6}}$ \\
\hline 4 & $\frac{1}{n_{u} A_{p s}}\left(\frac{a}{d}-\frac{1}{\tan \theta_{4}}\right)$ & $\left(a-m_{1} d\right) \cos \theta_{3}$ & $-\left(a-m_{2} d\right) \frac{\sin \theta_{3}}{\tan \theta_{4}}$ & 0 \\
\hline 5 & $\frac{m_{2} d}{n A_{c}} \frac{\sin \theta_{3}}{\tan \theta_{2}}$ & $\frac{1}{\tan \theta_{2}}$ & $-\frac{1}{\tan \theta_{1}}$ & 0 \\
\hline 6 & $\mathrm{~d} \sin \theta_{3}$ & $\frac{1}{\left(\sin \theta_{4}\right)^{3} A_{4}}$ & $\frac{1}{\left(\sin \theta_{2}\right)^{3} A_{2}}$ & $\frac{1}{A_{5}}$ \\
\hline 7 & $-\frac{P_{1}}{n_{u} A_{p s}}$ & $\left(a-m_{1} d\right) \cos \theta_{3}$ & $-\left(a-m_{2} d\right) \frac{\sin \theta_{3}}{\tan \theta_{4}}$ & 0 \\
\hline 8 & $-\frac{P_{2}}{n A_{c}} d \sin \theta_{3}$ & $\frac{m_{1}}{\tan \theta_{1}}$ & $-\frac{m_{2}}{\tan \theta_{2}}$ & 0 \\
\hline
\end{tabular}

* 1) $m_{1}=m, m_{2}=0.5 m$ for Model $1(m>1.0)$ and $m_{1}=2 m, m_{2}=m$ for Model $2(m \leq 1.0)$

2) $n_{u}=E_{s} / E_{c u}$ where $E_{s}$ : Elastic stiffness of reinforcement, $E_{c u}$ : Secant modulus of concrete at ultimate stage, where $\varepsilon_{0}^{\prime}=0.002$

$n=E_{s} / E_{c}$ where $E_{c}:$ Initial elastic stiffness of concrete

3) $A_{c}$ : Cross sectional area of flexural compression members, $A_{p s}:$ Cross sectional area of flexural tension members 
3. After replacing $\mathrm{k}$ from 1 to 4 to obtain $\mathrm{C}_{\mathrm{jk}}(\mathrm{k}=1$ 4), the coefficient $C_{j}(j=1-8)$ can be calculated as expressed in Eq. 3. By substituting the values of applied shear force, $V$, and obtained $C_{j}(\mathrm{j}=1-8)$ into Eq. 4 , the values of $F_{3}$ can be calculated. $F_{3}$ stands for the member force of member [3]. By applying the value of $F_{3}$ to Table 1, the member force of each diagonal compression member can be evaluated for comparing with $R_{i}$.

$$
\begin{array}{r}
C_{j}=C_{j 1}\left(C_{j 2}+C_{j 3}+C_{j 4}\right) \quad(j=1-8) \\
F_{3}=-\frac{1}{C_{1}+C_{2}+C_{3}}\left[V\left(C_{4}+C_{5}+C_{6}\right)+C_{7}+C_{8}\right]
\end{array}
$$

The initial elastic stiffness of concrete, $E_{c}$, is applied to flexural compression members which are considered to behave in the elastic range. The secant modulus of concrete at the ultimate stage, $E_{c u}$, is employed for diagonal compression members, in which the effect of existence of crack is considered. The strain at the maximum compressive strength, $\varepsilon_{0}$, is assumed to be 0.002 for assessing the value of $E_{c u}$.

Based on this calculating process, not only the easiness in calculating the shear carrying capacity of PC slender beams, but the critical flow of force can also be objectively predicted with the advantageous point of the simplified truss model. The applicability of this model will be discussed in the next section.

\section{CALCULATED RESULTS AND DISCUSSION}

To confirm the applicability of the proposed simplified truss model, the experimental results of normal and high strength of PC slender beams without transverse reinforcement are collected for comparing with the calculated results as tabulated in Table 4. From 9 references ${ }^{10)-18)}$, the reliability of experimental data was checked by using the finite element method as in the previous study ${ }^{1)}$. The tested results, which are not within the range $\pm 20 \%$ of the

\begin{tabular}{|c|c|c|c|c|c|c|c|c|c|c|c|c|c|c|c|c|}
\hline Researcher & No. & Specimen & $\mathrm{a} / \mathrm{d}$ & $\begin{array}{c}\mathrm{d} \\
(\mathrm{mm})\end{array}$ & $\begin{array}{c}\mathrm{f}_{\mathrm{c}^{\prime}} \\
(\mathrm{MPa})\end{array}$ & $\begin{array}{l}\mathrm{r}_{1} / \mathrm{r}_{\mathrm{s}}{ }^{*} \\
(\mathrm{~mm})\end{array}$ & $\begin{array}{c}\sigma_{\mathrm{u}} \\
(\mathrm{MPa})\end{array}$ & $\begin{array}{c}\sigma_{1} \\
(\mathrm{MPa})\end{array}$ & $\mathrm{m}$ & $\begin{array}{c}\mathrm{m}^{* *} \\
\text { (model) }\end{array}$ & Model & $\begin{array}{l}V_{\text {exp. }} \\
(\mathrm{kN})\end{array}$ & $\eta$ & $\begin{array}{l}\mathrm{V}_{\text {cal. }} \\
(\mathrm{kN})\end{array}$ & $\begin{array}{l}\mathrm{V}_{\text {exp }} / \\
\mathrm{V}_{\text {cal. }}\end{array}$ & $\begin{array}{c}\text { Failed } \\
\text { member }\end{array}$ \\
\hline Kobayashi $^{10}$ & 1 & 25 & 2.4 & 167 & 38.0 & $\mathrm{R} / \mathrm{R}$ & 0.0 & 3.9 & 1.5 & 1.5 & 1 & 63 & 0.59 & 58 & 1.09 & 3 \\
\hline \multirow{7}{*}{$\mathrm{PWRI}^{11)}$} & 2 & H3-35-30 & 3.0 & 350 & 92.0 & $100 / 150$ & -1.0 & 3.0 & 4.0 & 2.7 & 1 & 245 & 0.42 & 251 & 0.98 & 4 \\
\hline & 3 & H3-35-60 & 3.0 & 350 & 86.3 & $100 / 150$ & -2.0 & 6.0 & 2.5 & 2.5 & 1 & 284 & 0.44 & 311 & 0.91 & 4 \\
\hline & 4 & H3-35-90 & 3.0 & 350 & 70.3 & $100 / 150$ & -3.0 & 9.0 & 1.8 & 1.8 & 1 & 295 & 0.49 & 257 & 1.15 & 3 \\
\hline & 5 & H3-55-30 & 3.0 & 550 & 84.0 & $100 / 150$ & -1.0 & 3.0 & 3.8 & 2.7 & 1 & 228 & 0.45 & 282 & 0.81 & 4 \\
\hline & 6 & H3-75-30 & 3.0 & 750 & 88.5 & $100 / 150$ & -1.0 & 3.0 & 3.9 & 2.7 & 1 & 345 & 0.43 & 326 & 1.06 & 4 \\
\hline & 7 & H3-95-60 & 3.0 & 950 & 71.4 & $100 / 150$ & -2.0 & 6.0 & 2.3 & 2.3 & 1 & 586 & 0.49 & 583 & 1.01 & 3 \\
\hline & 8 & L3-35-60 & 3.0 & 350 & 40.6 & $100 / 150$ & -2.0 & 6.0 & 1.6 & 1.6 & 1 & 202 & 0.58 & 190 & 1.06 & 3 \\
\hline \multirow{6}{*}{ Mikata $^{12)}$} & 9 & P-0-20 & 3.2 & 140 & 41.9 & $R / R$ & 0.0 & 2.0 & 3.2 & 2.9 & 1 & 49 & 0.57 & 50 & 0.98 & 2 \\
\hline & 10 & P- $0-30$ & 3.2 & 140 & 43.0 & $\mathrm{R} / \mathrm{R}$ & 0.0 & 3.0 & 2.6 & 2.6 & 1 & 53 & 0.57 & 47 & 1.13 & 2 \\
\hline & 11 & $P-0-40$ & 3.2 & 140 & 43.0 & R/R & 0.0 & 4.0 & 2.1 & 2.1 & 1 & 48 & 0.57 & 49 & 0.98 & 2 \\
\hline & 12 & P- $20-40$ & 3.2 & 140 & 43.0 & $\mathrm{R} / \mathrm{R}$ & 2.0 & 4.0 & 2.1 & 2.1 & 1 & 52 & 0.57 & 49 & 1.06 & 2 \\
\hline & 13 & P $40-40$ & 3.2 & 140 & 43.0 & $\mathrm{R} / \mathrm{R}$ & 4.0 & 4.0 & 2.0 & 2.0 & 1. & 48 & 0.57 & 50 & 0.96 & 2 \\
\hline & 14 & HP-0-30 & 3.2 & 140 & 79.6 & $\mathrm{R} / \mathrm{R}$ & 0.0 & 3.0 & 3.7 & 2.9 & 1 & 74 & 0.46 & 72 & 1.03 & 2 \\
\hline \multirow{2}{*}{ Mikata $^{13)}$} & 15 & SPC-9 & 2.6 & 152 & 60.0 & R/R & -1.0 & 12.2 & 1.1 & 1.1. & 1 & 63 & 0.52 & 85 & 0.74 & 2 \\
\hline & 16 & $S P C-12$ & 2.6 & 149 & 72.1 & $\mathrm{R} / \mathrm{R}$ & -1.7 & 21.1 & 0.9 & 0.9 & 2 & 100 & 0.48 & 102 & 0.98 & 3 \\
\hline \multirow{6}{*}{$\operatorname{Arai}^{14)}$} & 17 & $N C-40$ & 3.0 & 167 & 36.4 & $50 / 50$ & -0.1 & 4.3 & 1.7 & 1.7 & 1 & 41 & 0.59 & 38 & 1.08 & 3 \\
\hline & 18 & $N C-80$ & 3.0 & 167 & 36.4 & $50 / 50$ & -0.2 & 8.3 & 1.2 & 1.2 & 1 & 46 & 0.59 & 42 & 1.10 & 2 \\
\hline & 19 & IC 40 & 3.0 & 167 & 36.5 & $50 / 50$ & -0.1 & 4.3 & 1.7 & 1.7 & 1 & 35 & 0.59 & 38 & 0.92 & 3 \\
\hline & 20 & LC-80 & 3.0 & 167 & 36.5 & $50 / 50$ & -0.2 & 8.3 & -1.2 & 1.2 & 1 & 36 & 0.59 & 42 & 0.86 & 2 \\
\hline & 21 & $S C .40$ & 3.0 & 167 & 37.4 & $50 / 50$ & -0.1 & 4.3 & 1.8 & 1.8 & 1 & 27 & 0.59 & 37 & 0.73 & 3 \\
\hline & 22 & SC. 80 & 3.0 & 167 & 37.4 & $50 / 50$ & -0.2 & 8.3 & 1.2 & 1.2 & 1 & 33 & 0.59 & 43 & 0.77 & 2 \\
\hline \multirow{3}{*}{ Tamura $^{15)}$} & 23 & $45 \mathrm{LC}-3$ & 3.8 & 1000 & 55.1 & $150 / 150$ & -1.1 & 2.6 & 4.1 & 3.4 & 1 & 505 & 0.53 & 406 & 1.24 & 3 \\
\hline & 24. & $45 \mathrm{~L}-5$ & 3.8 & 1000 & 53.3 & $150 / 150$ & -2.0 & 5.0 & 2.7 & 2.7 & 1. & 569 & 0.54 & 684 & 0.83 & 2 \\
\hline & 25 & $601 \mathrm{C}-5$ & 3.8 & 1000 & 68.7 & $150 / 150$ & -2.4 & 5.8 & 2.9 & 2.9 & 1 & 600 & 0.49 & 734 & 0.82 & 2 \\
\hline Hamada $^{16)}$ & 26 & $45 \mathrm{LC}-0$ & 3.5 & 300 & 47.0 & $65 / 150$ & -1.2 & 3.4 & 2.9 & 2.9 & 1 & 135 & 0.56 & 123 & 1.10 & 4 \\
\hline \multirow{3}{*}{ Sato $^{17)}$} & 27 & $3-11$ & 2.5 & 403 & 41.8 & $\mathrm{R} / 150$ & -3.1 & 8.9 & 1.1.1 & 1.1 & 1 & 171 & 0.57 & 193 & 0.89 & 3 \\
\hline & 28 & $4-6$ & 3.2 & 337 & 40.1 & $50 / 50$ & -5.0 & 14.0 & 1.0 & 1.0 & 2 & 170 & 0.58 & 185 & 0.92 & 3 \\
\hline & 29 & $4-12$ & 3.1 & 353 & 39.7 & $50 / 50$ & -4.7 & 14.5 & 1.0 & 1.0 & 2 & 162 & 0.58 & 190 & 0.85 & 3 \\
\hline \multirow{2}{*}{$\mathrm{Kar}^{18)}$} & 30 & A-1 & 5.1 & 175 & 35.9 & $100 / 100$ & -1.0 & 6.0 & 2.5 & 2.5 & 1 & 26 & 0.59 & 23.0 & 1.13 & 2 \\
\hline & 31 & A-2 & 5.1 & 175 & 34.8 & $100 / 100$ & 0.0 & 5.0 & 2.6 & 2.6 & 1 & 24 & 0.60 & 23.0 & 1.04 & 2 \\
\hline \multirow{2}{*}{\multicolumn{3}{|c|}{${ }^{*}: R$ stands for a roller }} & \multirow{2}{*}{\multicolumn{11}{|c|}{ Italic characters: Prestressed reinforced concrete beams }} & AVE. & 0.97 & \\
\hline & & & & & & & & & & & & & & C.V. & 0.13 & \\
\hline
\end{tabular}

Table 4 Outline of the experimental data and the comparison with the calculated results $(N=31)$ 
analytical result, are excluded from the list of targets. There are 31 experimental data left as the targets in this calculation. For the experimental data of $\mathrm{Kar}^{18)}$, the reliability of data was additionally checked by using the nonlinear finite element analysis in DIANA system. Since the width of bearing plates was not mentioned in the reference, $100 \mathrm{~mm}$ is applied as the possible value of width of bearing plates. The outline of the specimens and comparisons between the experimental and calculated results are summarized in the table. All specimens failed by the shear compression mode of failure. From the collected data, the values of $a / d$ vary from 2.4 to 5.1 , and the values of $d$ change in the range of 140 to $1000 \mathrm{~mm}$. The values of $\sigma_{l}$ vary from 2.0 to $21.0 \mathrm{MPa}$ including all 4 types of stress distribution. In calculation, for the cases in which the loading roller was applied, $50 \mathrm{~mm}$ is assumed as an alternative value for small width of bearing plates. Four diagonal compression members are considered in order to find out the one which causes the shear compression mode of failure in each case of calculation. The number of diagonal compression member shown in Fig.12, which leads the beam to a failure, is also summarized in Table 4.

It is evident that the proposed simplified truss model yields the well-predicted results compared with the experimental results in many conditions of geometric properties, concrete properties, level of prestressing forces and the types of stress distribution. There are some cases, which show somewhat disagreement between the test and calculated results. For example in the experimental data from Arai, et.al ${ }^{14)}$, even though the values of $f_{c}$ ' are quite same, the lightweight PC beams (LC and SC series) provided the lower shear carrying capacity than expectation compared with the normal ones (NC series). By comparing with other cases in which the lightweight aggregates were also used, if the shear carrying capacity of the beams is mainly depending on the compressive strength of concrete, the overestimated results should not be obtained (as in SC series).

In order to verify the accuracy in prediction of the model, the crack patterns at the ultimate stage are used to compare with the critical members of the predicted results. The bold dashed line represents the critical member of each case. The specimens which are predicted to fail by the members [2], [3], and [4] are illustrated as the examples in Fig. 14. The predicted critical member of the specimens P-40-40 and LC-80 (Fig. 14(a)) show the similar inclinations as results comparing with the actual critical crack. For the specimen P-40-40, it can be

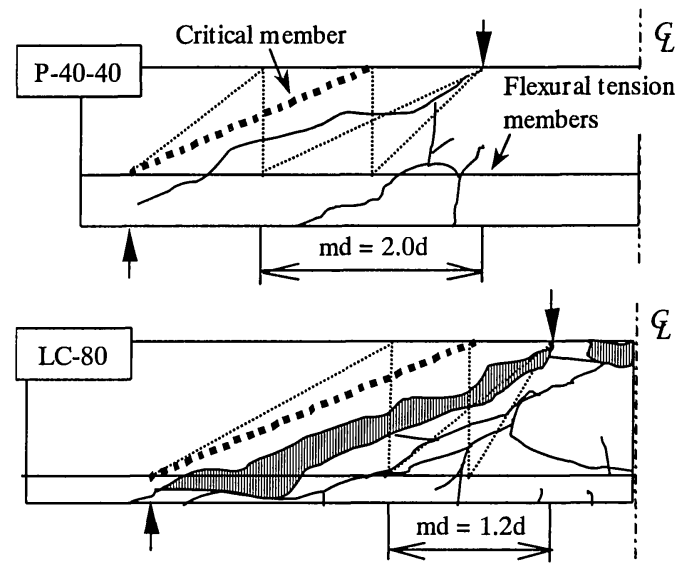

(a) Critical member : Member [2]
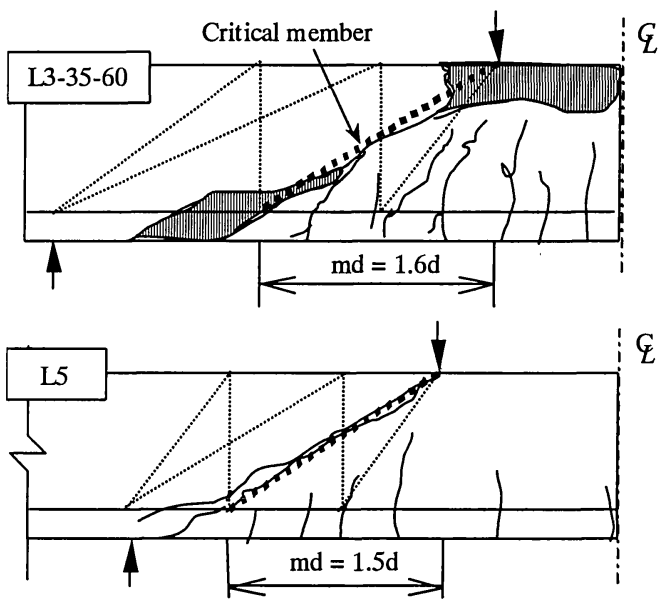

(b) Critical member : Member [3]
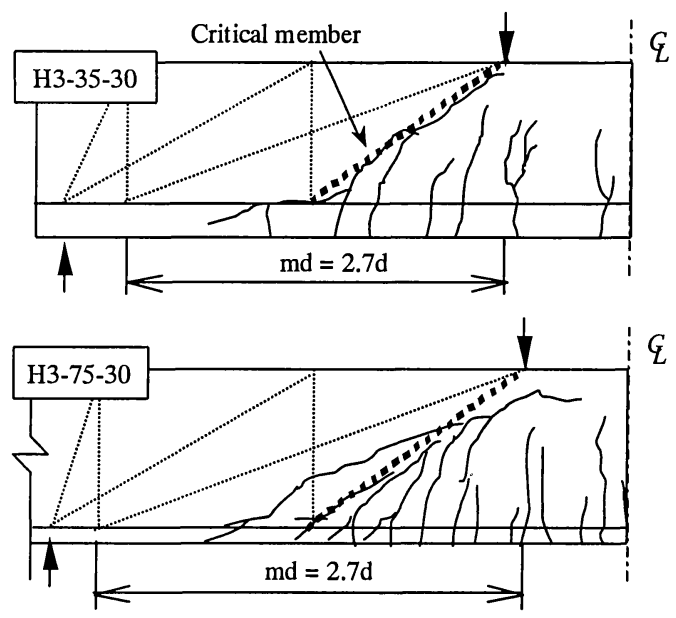

(c) Critical member : Member [4]

Fig. 14 Critical members and actual crack patterns 
said that the proposed model is applicable for estimating the crack pattern even in case where $\sigma_{u}$ is under compression (rectangular stress distribution). As the excellent predictions in Fig. 14(b), the accuracy in prediction in cases of the specimens L3-35-60 and L5 (lightweight concrete) is confirmed. It implies that this proposed model is applicable to predict the failure patterns of the lightweight PC slender beams. Additionally, this proposed model is also utilizable to predict the prestressed reinforced concrete beams as the results of specimens L5 and LC-80. For specimens predicted to fail by member [4] (Fig. 14(c)), $\mathrm{H} 3-35-30(d=350 \mathrm{~mm})$ and $\mathrm{H} 3-75-30(d=750 \mathrm{~mm})$, the good agreement between the critical diagonal compression member and the crack patterns can be observed. It means that this model can be applied to high strength PC slender beams with the wide range of effective depth.

In the proposal of value of $m$ in terms of significant parameters in Section 2(3), there are some calculated results which show the different tendency to the proposed relationships, for example in Fig. 7(d). These cases are the high strength concrete beams with high level of prestressing force. Among the collected data, excepting the geometric properties, the levels of prestressing and compressive strength of the experiments tested by Mikata ${ }^{13)}$ are closed to the mentioned cases. It is found that the satisfactorily predicted results are obtained as shown in Table 4. Moreover, the good agreement of calculated results of the cases of high strength concrete beams in the collected data are also obtained. In Fig. 7(b), there is a slight difference to the proposed relationship in case of $a / d=4.5$ and the value of $\sigma_{l}$ is in the middle level $(5 \sim 9 \mathrm{MPa})$. In the collected data, the shear carrying capacity of the experiments tested by $\mathrm{Kar}^{18)}$, where the value of $a / d$ is quite large, can be properly predicted. Therefore, it can be said that the values of $a / d$ and $f_{c}$ ' do not influence strongly on the prediction of shear carrying capacity in terms of the determining of $m$. But they are directly incorporated as the essential parameters in the calculation of shear carrying capacity. The prestressing level and its distribution are considered to give the strong effect to the inclination of critical stress (determination of $m$ ). From the limited data in parametric study, even the equation for predicting $m$ is approximated based on the simplicity, the suitable prediction can also be obtained.

Furthermore, the comparison between the calculated shear carrying capacity by the proposed simplified truss model (Proposed) and $\mathrm{M}_{\mathrm{cr}}$ method $\left(M_{c r}\right)^{4)}$ is performed and summarized in Fig. 15. It is

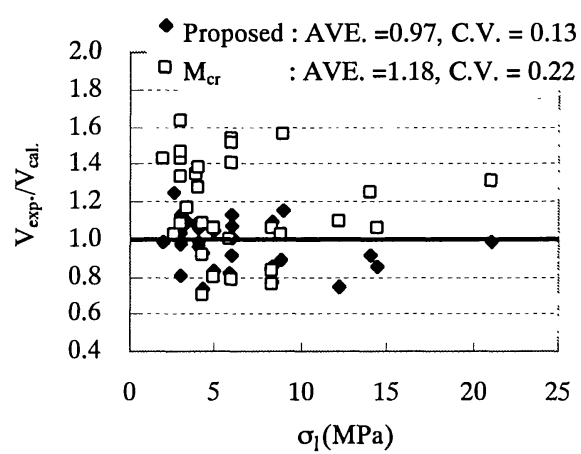

Fig. 15 Comparison in shear carrying capacity between the proposed model and $\mathrm{M}_{\mathrm{cr}}$ method

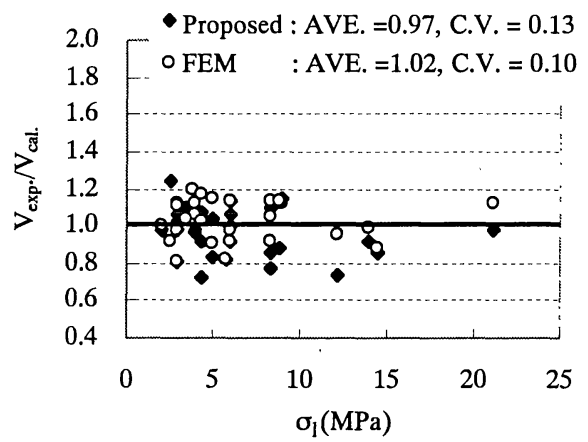

Fig. 16 Comparison in shear carrying capacity between the proposed model method and FEM

manifest in the results that, in the applied range of $\sigma_{l}$, the proposed model yields the superior accuracy and reliability in prediction with an average value (AVE.) of 0.97 and a coefficient of variation (C.V.) of 0.13 , while $\mathrm{M}_{\mathrm{cr}}$ method provides the results which AVE. $=1.18$ and C.V. $=0.22$. The analytical results of FEM in DIANA system are also compared with the results of proposed method as shown in Fig. 16. The FEM provides the results which AVE. $=1.02$ and C.V. $=0.10$. Even though the proposed model yields a bit inferior accuracy in prediction compared with ones of FEM, it can be said that this level of accuracy is considered to be adequate compared with its simplicity in calculation.

From the observation of collected experimental data, Model 2 is suitable for applying to PC beams with a high value of lower fiber stress. With the contemporary requirement of structures providing the high shear resisting capacity, the reliable approach for designing PC beams with high prestressing force become necessary. Even though the number of referred specimen fitting with Model 2 is small, Model 2 is also proposed in advanced for the practical way in future design. 


\section{CONCLUDING REMARKS}

In this research, the understandable explanation of failure mechanism of PC slender beams without transverse reinforcement can be obtained from the parametric study applying the finite element analysis. From the main investigation in the effects of prestressing force with the type of stress distribution, with the increase in value of lower fiber stress, the inclination of critical stress flow becomes steeper. In case of considerably high value of lower fiber stress, the steep stress flow becomes weak. Whereas the stress flow curvedly transferring to support is remarkable and it becomes the critical stress flow in that case. Moreover, it is apparent that the influence on the shear failure mechanism due to the variation of the upper fiber stress (types of stress distribution) cannot be neglected. It is the verification to point out the severe shortcomings of the current methods. With the additional variations on values of $a / d$, the effective depth and the compressive strength of concrete in the analysis, the tendency of inclinations of the concentrated stress flow can be proposed in term of $m$, where $m=\cot \theta$ and $\theta$ is the angle of estimated slope of the concentrated stress flow. For evaluating the shear carrying capacity of PC slender beams, the simplified truss model with a small degree of freedom has been developed. In this study, the shear carrying capacity can be easily calculated by using the equivalent elastic analysis. The thickness of diagonal compression members assessing from FEM results is estimated with the consideration of effects of bearing plates and effective depth. By adopting the evaluated thickness together with the value of $m$, the excellent correlation with the experimental data can be obtained. It can be concluded that the simplified truss model is easily applicable to evaluate the shear carrying capacity of PC slender beams without transverse reinforcement. Furthermore, the failure patterns are also satisfactorily predicted matching with the actual failure. It is evident that this proposed model is able to completely respond the 3 requirements in order to cover the shortcomings of the current methods.

\section{REFERENCES}

1) Tamura, S., Hamada, Y., Lertsamattiyakul, M. and Niwa, J.: A Study on Evaluation Methods of Shear Carrying Capacity of Prestressed Concrete Beams with Rectangular Cross Section, Journal of Prestressed Concrete, Vol. 45, No.6, pp.101-110, Nov. 2003.
2) ACI: Building Code Requirements for Structural Concrete and Commentary-ACI318-99, 1999.

3) JSCE: Standard Specification for Concrete Structures [Structural Performance Verification], 2002.

4) Ito, T., Yamaguchi, T. and Ikeda, S.: Flexural Shear Behavior of Precast Segmental PC Beam, Proceedings of the JCI, Vol. 16, No.2, pp.967-972, 1994.

5) Popovics, S.: A Numerical Approach to the Complete Stress-Strain Curve of Concrete, Cement and Concrete Research, Vol. 3, pp. 583-599, 1973.

6) Japan Road Association: Specification for Highway Bridges [Earthquake-resistant design], Mar. 2002.

7) Schlaich, J., Schäfer, I. and Jennewein, M.: Towards a Consistent Design of Structural Concrete, Journal of PCI, Vol. 32, No. 3, pp.74-150, 1987.

8) Niwa, J.: Equation for Shear Strength of Reinforced Concrete Deep Beams Based on FEM Analysis, Concrete Library of JSCE, No.4, pp.283-295, 1984.

9) Vecchio, F.J. and Collins, M.P.: The Modified Compression Field Theory for Reinforced Concrete Elements Subjected to Shear, ACI Structural Journal, Vol. 83, No.2, pp.219-231, 1986.

10) Kobayashi, K.: Effects of Introducing Prestress on Shear Resistance of Concrete Beams, Proceedings of Cement and Concrete, No. 46, pp.750-755, 1992.

11) Public Works Research Institute: Study on Shear Strength of PC Beams with High Strength Concrete, Joint Research on Design Method of High Strength Concrete Structures, No. 122, 1995.

12) Mikata, Y., Inoue, S., Kobayashi, K. and Nieda, T.: Effect of Prestress on Shear Capacity of Prestressed Concrete Beams, Journal of Materials, Concrete Structures and Pavements, JSCE, No.669/V-50, pp.149-159, Feb. 2001.

13) Mikata, Y.: The Study on Shear Strength Characteristics of Concrete Structural Members, Doctoral Thesis, Dept. of Civil Eng., Osaka Institute of Technology, 2002.

14) Arai, Y. and Yaginuma, Y.: Shear Behavior of PC Beams Using Light-weight Concrete, Proceedings of The $10^{\text {th }}$ Symposium on Developments in Prestressed Concrete, pp.545-550, Oct. 2000.

15) Tamura, S., Hamada, Y., Maehori, S. and Niwa, J.: Shear Strength Characteristics of Large Scale PC Beams Using Super Lightweight Concrete, Proceedings of the JCI, Vol. 23, No.3, pp.709-714, 2001.

16) Hamada, Y., Tamura, S., Maehori, S. and Niwa, J.: Ultimate Shear Capacity of Prestressed Concrete Beams Using High Performance Lightweight Aggregates, Proceedings of The $9^{\text {th }}$ Symposium on Developments in Prestressed Concrete, pp.739-744, Oct. 1999.

17) Sato, T., Ishibashi, T., Yamashita, H. and Takada, S.: Shear Strength and Modes of Failure of Prestressed Concrete Beams, Proceedings of the JCI, Vol. 9, No.2, pp.323-328, 1987.

18) Kar, J. N.: Shear Strength of Prestressed Concrete Beams Without Web Reinforcement, Magazine of Concrete Research, Vol. 21, No.68, pp.159-170, Sep. 1969. 